\title{
Otomatik Gerilim Regülatörü için Evrimsel Algoritma Tabanlı Filtreli PID Denetleyici Tasarımı
}

\author{
Büşra ÖZGENÇ ${ }^{1 *}$, Mustafa Şinasi AYAS², İsmail Hakkı ALTAŞ ${ }^{3}$ \\ 1,2,3Karadeniz Teknik Üniversitesi, Elektrik-Elektronik Mühendisliği Bölümü, Trabzon, Türkiye
}

*Sorumlu Yazar: busraozgenc@ktu.edu.tr

Geliș Tarihi: 15.04.2020

Kabul Tarihi: 29.05 .2020

\section{Öz}

Otomatik gerilim regülatör (OGR) sistemi, generatör terminal gerilimini belirtilen seviyede tutmak için güç sistemlerinde yaygın olarak kullanılır. OGR sisteminde farklı denetleyiciler kullanılarak generatör terminal geriliminin denetimi gerçekleştirilmektedir. Araştırmacılar yaptıkları çalışmalarda OGR sisteminin dinamik performansını iyileştirmeyi ve sürekli durum hatasını sıfira indirmeyi hedeflemektedir ve bu kapsamda evrimsel algoritmalar yardımıla denetleyici tasarlamaktadır. Evrimsel algoritmalar, denetleyici parametrelerini belirlenen bir amaç fonksiyonunu göz önüne alarak optimal bir şekilde ayarlamak için yaygın olarak kullanılmaktadır. Bu çalışmada, bir OGR sisteminin denetimi için iki farklı filtreli oransal-integral-türevsel (PID-F) denetleyici tasarlanmıştır. Denetleyicilerin parametrelerini ayarlamak için atom arama optimizasyon (AAO) ve parçacık sürüsü optimizasyon (PSO) algoritmaları kullanılmıştır. Her bir denetleyici için OGR sisteminin geçici yanıt analizi, frekans analizi, dayanıklılık analizi Matlab/Simulink programında incelenmiş ve performans karşılaştırması yapılmıştır. Elde edilen sonuçlara göre, AAO algoritmasının PSO algoritmasından daha iyi sonuçlar verdiği görülmüş̧ür. Ayrıca, AAO algoritması ile tasarlanmış PID-F denetleyicinin, AAO, PSO, biyocoğrafyaya dayalı optimizasyon (BDO) ve yapay arı koloni (YAK) algoritmaları ile ayarlanmış klasik PID denetleyicilere göre geçici yanıt karakteristiklerini iyileştirdiği ve sistemin kararlılığını ve dayanıklılığını arttırdığı sonucuna varılmıştır.

Anahtar Kelimeler: Atom arama optimizasyonu, OGR sistemi, PID-F denetleyici, Parçacık sürüsü optimizasyonu.

\section{Design of Evolutionary Algorithm Based PID Controller with filter for an Automatic Voltage Regulator}

\begin{abstract}
The automatic voltage regulator (AVR) system is commonly used in power systems to keep the terminal voltage of generator at a specified level. The terminal voltage level is controlled by using different controllers in an AVR sistem. Researchers aim to improve dynamic performance of the AVR system and to decrease the steady state error to zero by using different controllers in their studies. They design controllers by utilizing evolutionary algorithms. Evolutionary algorithms are widely used to optimally tune controller parameters according to predefined objective function. In this study, two different proportional-integral-derivative with filter (PID-F) controllers are designed for the AVR system. Atom search optimization (ASO) and particle swarm optimization (PSO) algorithms are used to tune the parameters of the controllers. For each controller, transient response analysis, frequency analysis, and robustness analysis are examined in Matlab/Simulink for the AVR system and performance comparison is made. The results indicate that the ASO algorithm achieves better results than the PSO algorithm. In addition, it is concluded that the PID-F controller designed with ASO algorithm improves the transient response characteristics, stability and robustness compared to the classical PID controller of which the parameters are tuned by ASO, PSO, Biogeography based optimization (BBO) and Artificial bee colony (ABC).
\end{abstract}

Keywords: Atom search optimization, AVR system, PID-F controller, Particle swarm optimization. 


\section{Giriş}

Güç sistemlerinde kullanılan elemanların dayanıklılığı ve ömrü, gerekli anma gerilim seviyesinin yüksek hassasiyetle sağlanmasıyla artırılabilir. Çünkü bu elemanlar anma gerilimi dikkate alınarak tasarlanmıştır. Ayrıca, hat kayıplarında etkili olan reaktif güç akışı bu gerilim değerine bağlıdır. Bu nedenle, gerilim seviyesinin istenen seviyede tutulması için kontrol edilmesi önemlidir (Gozde ve Taplamacioglu, 2011).

Hat kayıplarını azaltmaya yönelik yapılan gerilim kontrolü için otomatik gerilim regülatör (OGR) sistemleri kullanılmaktadır. OGR sistemi, generatör terminal gerilimini belirtilen seviyede tutmak için güç sistemlerinde yaygın olarak kullanılan bir kapalı çevrim kontrol sistemidir. OGR sistemleri, dinamik performansı geliştirmek için denetleyicilerle birlikte kullanılır. Klasik denetleyici yöntemlerinden biri olan oransal-integral-türevsel (PID) denetleyici, kullanım kolaylığı ve güçlü performansı nedeniyle OGR sistemlerinde yaygın olarak kullanılmaktadır (Bingul ve Karahan, 2018; Gozde ve Taplamacioglu, 2011). Bir PID denetleyici tasarımı geleneksel yöntemlerle yapılabileceği gibi meta-sezgisel optimizasyon algoritmaları kullanılarak da yapılabilir. Ziegler-nichols yöntemi ve kazanç-faz marjin yöntemi gibi geleneksel yöntemlerin zayıf kapalı çevrim yanıtları sağlaması ve doğrusal olmayan sistemlerde uygulama zorluğu gibi dezavantajları vardır (Coelho, 2009). Bu nedenle, araştırmacılar son yıllarda yaygın olan optimizasyon algoritmalarını kullanarak OGR sistemi için PID denetleyici parametrelerini ayarlamaktadır. Literatürde, guguk kuşu algoritması (Bingul ve Karahan, 2018), karınca koloni optimizasyonu (Blondin ve ark., 2018), simbiyotik organizma arama algoritması (Çelik ve Durgut, 2018), karınca aslanı optimizasyonu (Bourouba ve ark., 2019), arılar algoritması ve ateşböceği algoritması (Hameed ve ark., 2019), çekirge optimizasyon algoritması (Hekimoglu ve Ekinci, 2018), biyocoğrafyaya dayalı optimizasyon (Guvenc ve ark., 2016), yapay arı koloni algoritması (Gozde ve Taplamacioglu, 2011), sinüs-kosinüs algoritması (Hekimoglu, 2019), parçacık sürüsü optimizasyon algoritması (Al Gizi, 2018), gri kurt optimizasyon algoritması (Verma ve ark., 2017), genetik algoritma (Suribabu ve Chiranjeevi, 2016), bakteri yem arama optimizasyon algoritması (Anbarasi ve Muralidharan, 2016) gibi optimizasyon algoritmaları OGR sisteminde PID denetleyici parametrelerini optimal ayarlamak için kullanılmıştır. Bununla birlikte kesir dereceli PID denetleyici (Tang ve ark., 2017), kesirli yüksek dereceli diferansiyel geri beslemeli denetleyici (Ayas, 2019), oransal-integral-türev-ikinci dereceden türev (PIDD²) denetleyici (Sahib, 2015) ve oransalintegral-türev-hızlanma (PIDA) denetleyici (Sambariya ve Paliwal, 2016) gibi farklı denetleyiciler de OGR sistemlerinde kullanılmıştır. Fakat bu çalışmaların sayısı, PID denetleyici ile yapılanların yanında oldukça sınırlı sayıdadır.

Yukarıda bahsedilen çalışmalardaki ortak amaç, OGR sistem performansını yüzde aşma oranı, oturma süresi ve yükselme süresi gibi geçici yanıt karakteristikleri açısından iyileştirmektir. Bu amaç 
doğrultusunda PID denetleyici tasarımları için farklı evrimsel algoritmalardan faydalanmışlardır. Fakat gerçekleştirilen bu tasarımlarda PID denetleyicinin türev vuruş etkisi göz önüne alınmamıştır. Türev vuruş etkisi, referans işaretindeki ani sıçramalar ile meydana gelir. Böyle bir durumda hata işaretinin ani sıçramasına neden olunur ki bu durumda hatanın türevi çok büyük bir değere ulaşarak denetleyicinin kısa bir süre için de olsa doyuma ulaşmasına yol açar. Türev vuruş etkisini önlemek için PID denetleyicinin türevsel bileşenine alçak geçiren filtre eklenir.

$\mathrm{Bu}$ çalışmanın amacı, OGR sisteminin dinamik performansını geliştirmek için yukarıda bahsedilen çalışmaların aksine bir filtreli PID (PID-F) denetleyici tasarlamaktır. Bu kapsamda denetleyicinin parametreleri ve filtrenin kazancını optimize etmek için hem atom arama optimizasyon (AAO) hem de parçacık sürüsü optimizasyon (PSO) algoritmaları kullanılmıştır. Ayrıca filtreli yapının klasik PID denetleyici ile karşılaştırmasını yapmak için de parametreleri optimize edilmiş dört farklı klasik PID denetleyici kullanılmıştır. Bu dört denetleyicinin ikisi bu çalışma kapsamında AAO ve PSO algoritmaları ile tasarlanmışken, diğer iki PID denetleyici ise BDO ve YAK algoritmaları kullanılarak tasarlanmış literatürde var olan PID denetleyicilerdir. Hem PID-F hem de PID denetleyicili OGR sistemlerinin benzetimi gerçekleştirilmiş ve performans karşılaştırması yapılmıştır. Karşılaştırmada ilk olarak OGR sisteminin basamak yanıtından elde edilen geçici yanıt karakteristikleri göz önünde bulundurulmuştur. Yüzde aşma oranı, oturma süresi ve yükselme süresinin yanı sıra sürekli durum hatası da dikkate alınmıştır. Ayrıca OGR sisteminin kararlılık analizi (hem bode analizi hem de kutup-sıfır analizi) ve dayanıklılık analizi de gerçekleştirilmiştir.

Makalenin geri kalan kısmı şu şekilde düzenlenmiştir: Bölüm 2'de, OGR sistem modeli, makalede kullanılan optimizasyon algoritmaları ve bu algoritmaları kullanarak önerilen PID-F denetleyicilerin tasarımı verilmiştir. OGR sisteminin benzetim sonuçları Bölüm 3 'te verilmiştir. Son olarak, değerlendirmeler verilir.

\section{Materyal ve Metot}

\subsection{OGR Sisteminin Modellenmesi}

Yaygın kullanılan bir OGR sistemi, Şekil 1'de gösterildiği gibi her biri birinci dereceden transfer fonksiyonu ile modellenebilen yükselteç, uyarıcı, generatör ve sensör bileşenlerinden oluşmaktadır. Bu birinci dereceden transfer fonksiyonları için bir kazanç sabiti K ve bir zaman sabiti $\tau$ gereklidir. $\mathrm{Bu}$ sabitlerin parametre aralıkları ve bu çalışmada kullanılan değerleri Tablo 1'de verilmiştir. 


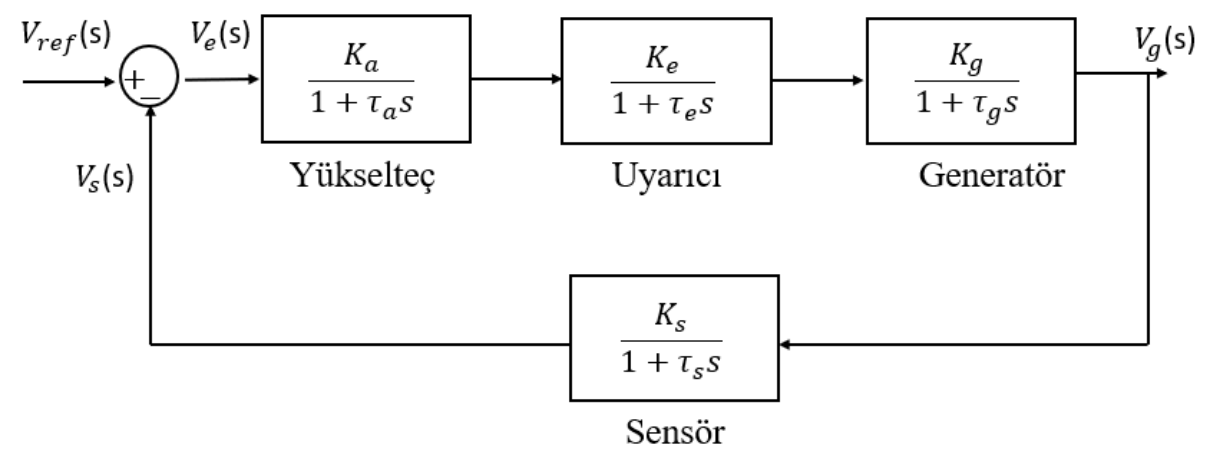

Şekil 1. Denetimsiz OGR sisteminin blok diyagramı

Tablo 1. OGR bileşenlerinin parametreleri (Gaing, 2004; Ayas, 2019)

\begin{tabular}{c|l|l}
\hline Bileşenler & Parametre limitleri & Kullanılan değerler \\
\hline Yükselteç & $10 \leq K_{a} \leq 40,0.02 \leq \tau_{a} \leq 0.1$ & $K_{a}=10, \tau_{a}=0.1$ \\
Uyarıcı & $1 \leq K_{e} \leq 10,0.4 \leq \tau_{e} \leq 1$ & $K_{e}=1, \tau_{e}=0.4$ \\
Generatör & $0.7 \leq K_{g} \leq 1,1 \leq \tau_{g} \leq 2$ & $K_{g}=1, \tau_{g}=1$ \\
Sensör & $0.9 \leq K_{s} \leq 1.1,0.001 \leq \tau_{s} \leq 0.06$ & $K_{s}=1, \tau_{s}=0.01$ \\
\hline
\end{tabular}

Tablo 1'de verilen parametre değerleri yerine yazıldığında denetimsiz OGR sisteminin kapalı çevrim transfer fonksiyonu eşitlik (1)'de verildiği gibidir.

$$
G_{O G R}=\frac{0.1 s+10}{0.0004 s^{4}+0.045 s^{3}+0.555 s^{2}+1.51 s+11}
$$

OGR sisteminin herhangi bir denetleyici kullanılmadan elde edilen birim basamak yanıtı Şekil 2 'de verilmiştir. Şekilden görülebileceği gibi, generatör çıkış geriliminde \%50'ye yakın aşma, geç oturma süresi ve gözardı edilemeyecek sürekli durum hatası vardır. Bu nedenle, minimum aşma, erken oturma süresi ve minimum sürekli durum hatası elde etmek için iyi tasarlanmış bir denetleyici gereklidir. 


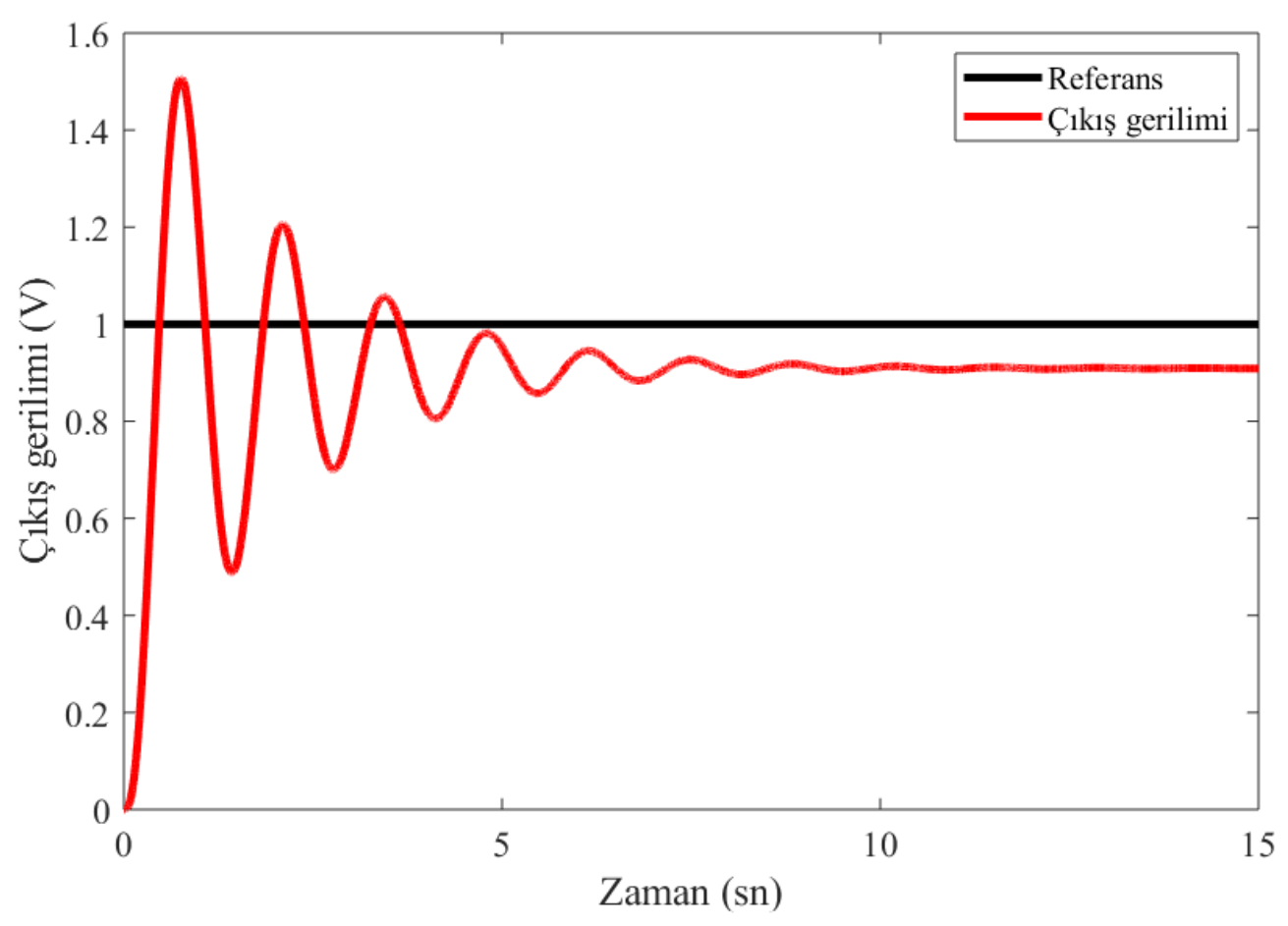

Şekil 2. Denetimsiz OGR sisteminin basamak yanıtı

\subsection{Atom arama optimizasyonu}

Zhao, Wang ve Zhang tarafından geliştirilen atom arama optimizasyon (AAO) algoritması, moleküler dinamiklere dayanmaktadır. AAO algoritmasında arama uzayındaki her atomun pozisyonu, kütlesi tarafından ölçülen bir çözümü temsil etmektedir. Popülasyon içindeki tüm atomlar aralarındaki mesafeye göre birbirini itecek veya çekecektir. Ağır atomların hızı daha düşük olduğu için yerel çözüm bulmada başarılıdır, hafif atomlar ise hızı daha fazla olduğu için arama uzayında daha geniş bir çözüm alanı bulabilmektedir. Bu algoritmada kullanılan hız ve pozisyon güncelleme denklemleri sırasıyla eşitlik (2) ve (3)’ te verilmiştir (Zhao ve ark, 2019).

$$
\begin{aligned}
& v_{i}^{d}(t+1)=\operatorname{rand}_{i}^{d} v_{i}^{d}(t)+a_{i}^{d}(t) \\
& x_{i}^{d}(t+1)=x_{i}^{d}(t)+v_{i}^{d}(t+1)
\end{aligned}
$$

Eşitlik (2) ve (3)’te $t$ iterasyon sayısıdır, $i$ atomun indeksidir, d değişken boyut sayısı, $a_{i}$ atom i'nin hızlanma katsayısı, rand 0 ile 1 arasında rastgele bir sayı, $v_{i}$ ve $x_{i}$ sirasıyla atom i'nin hizı ve pozisyonudur. Algoritma tasarımında Matlab programı kullanılmıştır. Algoritma akış çizelgesi Şekil 3’te verilmiştir. 


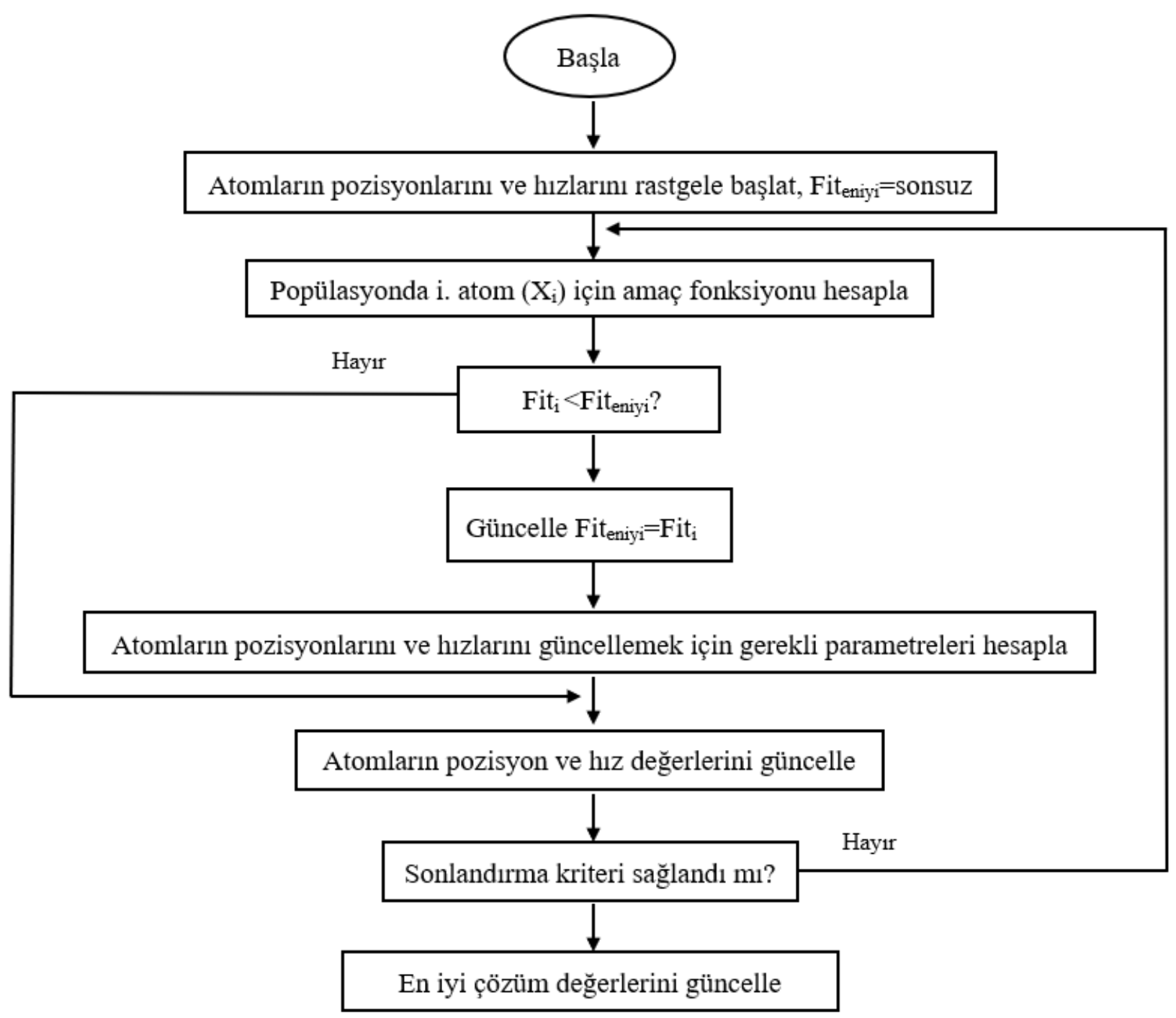

Şekil 3. AAO algoritması akış çizelgesi

\subsection{Parçacık sürüsü optimizasyonu}

Kennedy ve Eberhart tarafindan geliştirilen parçacık sürüsü optimizasyon algoritması, sürüye dayalı evrimsel bir algoritmadır (Kennedy ve Eberhart, 1995). Algoritma, yiyeceğe en yakın kuşun konumuna göre sürüdeki kuşların hareketine dayanmaktadır. Sürünün hareketini modellemek için parçacıkların konum ve hız güncelleme denklemleri kullanılır. Hız ve pozisyon denklemleri sırasıyla aşağıda verilmiştir.

$$
\begin{aligned}
& V_{i}^{k+1}=w^{k} V_{i}^{k}+c_{1} r_{1}\left(P_{\text {eniyi }}^{k}-X_{i}^{k}\right)+C_{2} r_{2}\left(G_{\text {eniyi }}^{k}-X_{i}^{k}\right) \\
& X_{i}^{k+1}=X_{i}^{k}+V_{i}^{k+1}
\end{aligned}
$$


Eşitlik (4) ve (5)’te $k$ yineleme sayısıdır, $i$ parçacığın indeksidir, $w$ hızı doğrudan etkileyen atalet ağırlığıdır, $c_{1}$ ve $c_{2}$ sırasıyla bilişsel ve sosyal sabitler olarak adlandırılan ivme faktörleridir, $r_{1}$ ve $r_{2} 0$ ile 1 arasında rastgele sayılardır, $P_{\text {eniyi }}$ en iyi yerel çözümdür, $G_{e n i y i}$ en iyi küresel çözümdür, $V_{i}$ ve $X_{i}$ sırasıyla parçacık i'nin hızı ve konumudur. Genellikle c1 ve c2 2' ye ayarlanırken, w 0.9'dan 0.4'e lineer olarak azalır (Gaing, 2004). Algoritma tasarımında Matlab programı kullanılmıştır. Algoritmanın akış çizelgesi Şekil 4’te verildiği gibidir.

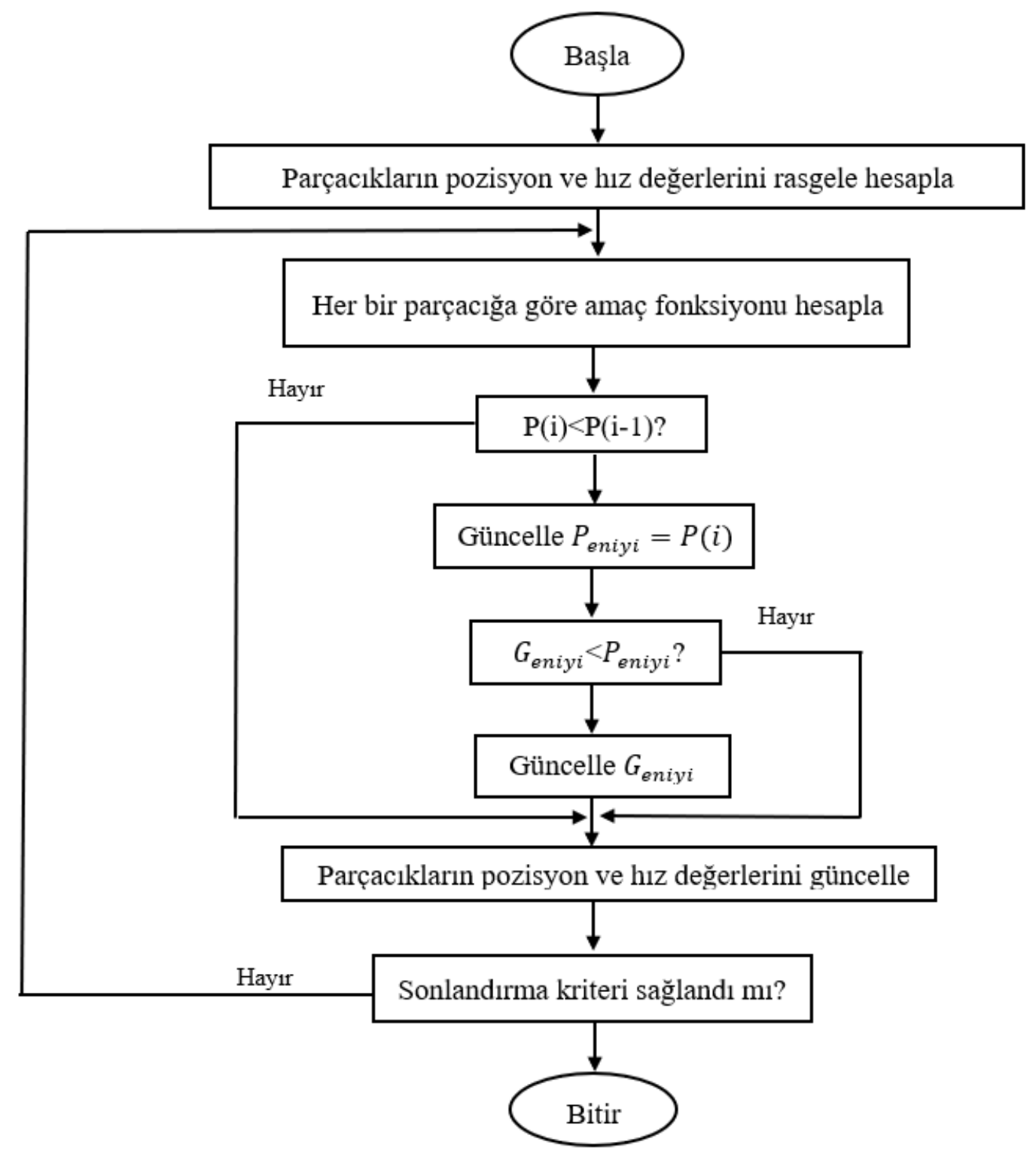

Şekil 4. PSO algoritması akış çizelgesi

\subsection{OGR Sistemi için PID-F Denetleyici Tasarımı}

OGR sistem performansını iyileştirmek için AAO ve PSO optimizasyon algoritmaları yardımıyla PID-F denetleyici tasarımı benzetim ortamında gerçekleştirilmiştir. PID-F denetleyici içeren kapalı çevrim OGR sistemi Şekil 5’te gösterilmektedir. Kapalı çevrim OGR sistem 
parametreleri Tablo 1'de verildiği gibi kullanılmıştır. Tasarlanan PID-F denetleyici transfer fonksiyonu eşitlik (6)'da verilmiştir.

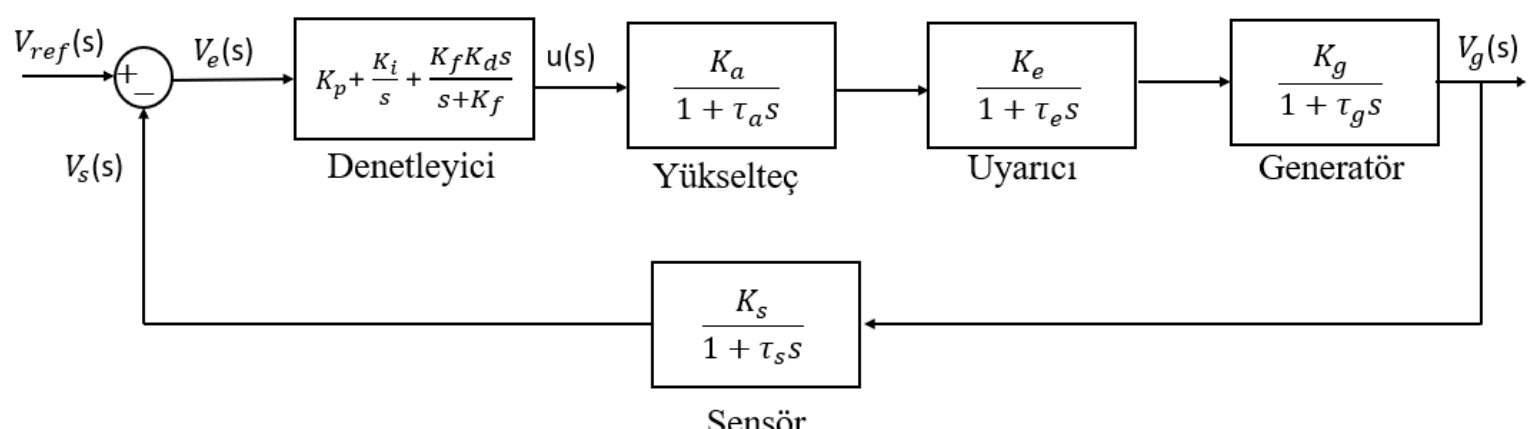

Şekil 5. PID-F denetleyicili kapalı çevrim OGR sisteminin blok diyagramı

$$
C_{P I D-F}=\frac{\left(K_{p}+K_{f} K_{d}\right) s^{2}+\left(K_{i}+K_{f} K_{p}\right) s+K_{i} K_{f}}{s^{2}+K_{f} s}
$$

Şekil 5’te verilen PID-F denetleyicili kapalı çevrim OGR sisteminin transfer fonksiyonu eşitlik (7)'de verilmiştir.

$$
G_{\text {OGR-PIDF }}=\frac{\left(0.1 K_{p}+0.1 K_{f} K_{d}\right) s^{3}+\left(10 K_{p}+10 K_{f} K_{d}+0.1 K_{i}+0.1 K_{f} K_{p}\right) s^{2}+\left(10 K_{i}+10 K_{f} K_{p}+0.1 K_{i} K_{f}\right) s+10 K_{i} K_{f}}{0.0004 s^{4}+0,0454 s^{3}+\left(0.555+10 K_{p}+10 K_{f} K_{d}\right) s^{2}+\left(1.51+10 K_{i}+10 K_{f} K_{p}\right) s+\left(1+10 K_{i} K_{f}\right)}
$$

Şekil 5’ten de görüleceği üzere PID-F denetleyicisinin birbirinden bağımsız dört parametresini yani oransal kazanç $K_{p}$, integral kazanç $K_{i}$, türevsel kazanç $K_{d}$ ve filtre kazancı $K_{f}$ ' yi optimum şekilde ayarlamak gerekmektedir. PID-F denetleyicinin ilgili parametreleri hem AAO hem de PSO algoritmaları kullanılarak eşitlik (8) 'de verilen amaç fonksiyonunu minimum yapacak şekilde ayarlanmıştır. Eşitlik (8) 'de, Mp, Ess, ts ve tr sırasıyla yüzde aşma oranı, sürekli durum hatası, oturma süresi ve yükselme süresini temsil etmektedir. Bu çalışmada kullanılan amaç fonksiyonu (Gaing,2004) çalışmasında tanımlanmıştır ve geçici yanıt karakteristiklerine ve sürekli durum hatasına dayanmaktadır.

$$
A F=(1-\exp (-1))(M p / 100+E s s)+\exp (-1)(t s-t r)
$$

Algoritmaların 4 boyutlu arama uzaylarının alt limitleri tüm parametreler için sıfırken, üst limitleri $K_{p}, K_{i}, K_{d}$ ve $K_{f}$ için sırasıyla 2, 1, 1 ve 500 olarak alınmıştır. Bu çalışmada kullanılan AAO ve PSO algoritmalarında, popülasyon ve iterasyon sayıları 50 alınmıştır ve algoritmaların başlangıç 
popülasyonları rastgele başladığı için $10 \mathrm{kez}$ çalıştırılmıştır.10 denemenin içinden en düşük amaç fonksiyonu değerinin elde edildiği denetleyici parametreleri Tablo 2'de verilmiştir. Önerilen PID-F denetleyicisindeki filtrenin etkisini göstermek için yukarıda bahsedilen aynı koşullar altında AAO ve PSO algoritmaları ile filtresiz klasik PID denetleyici tasarlanmıştır ve denetleyici parametreleri yine Tablo 2'de verilmiştir. Ek olarak, karşılaştırma yapmak amacıyla BDO ve YAK algoritmaları ile tasarlanmış PID denetleyici parametreleri de Tablo 2'de gösterilmektedir.

Tablo 2. PID-F ve PID denetleyici parametreleri ve karşılık gelen amaç fonksiyon değeri

\begin{tabular}{|c|c|c|c|c|c|c|}
\hline \multirow[t]{2}{*}{ Denetleyici } & \multicolumn{4}{|c|}{ Parametreler } & \multirow[t]{2}{*}{ Amaç fonksiyon değeri } & \multirow[t]{2}{*}{ İterasyon } \\
\hline & $\mathbf{K}_{\mathbf{p}}$ & $\mathbf{K}_{\mathbf{i}}$ & $\mathbf{K}_{\mathbf{d}}$ & $\mathbf{K}_{\mathbf{f}}$ & & \\
\hline AAO-PID-F & 0.65 & 0.4 & 0.24 & 460 & 0.041 & 35 \\
\hline AAO-PID & 1.88 & 0.31 & 0.41 & - & 0.062 & 38 \\
\hline PSO-PID-F & 0.68 & 0.42 & 0.25 & 494 & 0.044 & 45 \\
\hline PSO-PID & 2 & 0.36 & 0.43 & - & 0.062 & 23 \\
\hline $\begin{array}{l}\text { BDO-PID (Guvenc ve } \\
\text { ark., 2016) }\end{array}$ & 1.2464 & 0.5893 & 0.4596 & - & 0.3281 & - \\
\hline $\begin{array}{l}\text { YAK-PID (Gozde ve } \\
\text { Taplamacioglu, 2011) }\end{array}$ & 1.6524 & 0.4083 & 0.3654 & - & 0.4391 & - \\
\hline
\end{tabular}

\section{Bulgular ve Tartışma}

$\mathrm{Bu}$ çalışmada tasarlanan AAO-PID-F ve PSO-PID-F denetleyicilerinin OGR sistem kontrolündeki başarısını göstermek için ilgili filtreli denetleyiciler AAO-PID, PSO-PID, BDO-PID ve YAK-PID denetleyicileri ile kıyaslanmıştır. Kıyaslama yapmak için her bir denetleyici için ayrı ayrı olmak üzere OGR sistemin geçici yanıt analizi, kutup/sıfır analizi, bode analizi ve dayanıklılık analizi gerçekleştirilmiştir. Yapılan analizler ve elde edilen sonuçlar alt başlıklar halinde aşağıda verilmiştir.

\subsection{Geçici Yanıt Analizi}

Tablo 2'de parametre değerleri verilen PID-F ve PID denetleyiciler ayrı ayrı kullanılarak OGR sistemin birim basamak yanıtı elde edilmiştir. Farklı PID denetleyiciler ile denetlenmiş OGR sisteminin basamak yanıtları Şekil 6'da verilmektedir. Elde edilen yanıtların geçici yanıt karakteristikleri Tablo 3'te verilmektedir. Aynı zamanda kalıcı durum hatası ve performans metrik değerleri de Tablo 3'te sunulmuştur. Tablodaki ITAE ve ITSE metrikleri denetleyici performans karşılaştırması için literatürde yaygın olarak kullanılan metriklerdir. Bu performans metriklerinin ifadesi eşitlik (9) ve (10)' da sırasıyla verilmiştir. Sonuçlar göz önüne alındığında filtreli PID denetleyicilerin (AAO-PID-F ve PSO-PID-F) klasik PID denetleyicilere göre OGR sistem 
denetiminde daha başarılı olduğu anlaşılmaktadır. Çünkü en düşük amaç fonksiyon değeri AAO-PIDF ile 2. en düşük amaç fonksiyon değeri ise PSO-PID-F ile elde edilmiştir. Aynı zamanda AAO-PIDF ve PSO-PID-F ile elde edilen maksimum aşma oranı, oturma süresi, yükselme süresi ile amaç fonksiyonu (AF), ITAE ve ITSE metrik değerleri sırasıyla AAO-PID ve PSO-PID ile elde edilenlerden düşüktür ki bu sonuçta PID-F denetleyicisindeki filtrenin pozitif etkisini göstermektedir.

$$
\begin{aligned}
& \text { ITAE }=\int_{0}^{t} t|e(t)| d t \\
& \text { ITSE }=\int_{0}^{t} t e^{2}(t) d t
\end{aligned}
$$

Tablo 3. Farklı denetleyiciler için elde edilen geçici yanıt karakteristikleri ve performans metrikleri

\begin{tabular}{l|c|c|c|c|c|c|c}
\hline \multicolumn{1}{c|}{ Denetleyici } & $\begin{array}{c}\mathbf{M}_{\mathbf{p}} \\
\mathbf{( \% )}\end{array}$ & $\begin{array}{c}\mathbf{t}_{\mathbf{r}} \\
\mathbf{( s n )}\end{array}$ & $\begin{array}{c}\mathbf{t}_{\mathbf{s}} \\
\mathbf{( s n )}\end{array}$ & $\mathbf{E s s}$ & $\mathbf{A F}$ & ITAE & ITSE \\
\hline AAO-PID-F & 0 & 0.28 & 0.388 & 0.0007 & 0.041 & 0.036 & 0.0068 \\
AAO-PID & 0 & 0.292 & 0.456 & 0.003 & 0.062 & 0.056 & 0.026 \\
PSO-PID-F & 0.956 & 0.261 & 0.362 & 0.0009 & 0.044 & 0.037 & 0.0068 \\
PSO-PID & 0.482 & 0.283 & 0.442 & 0.0003 & 0.062 & 0.0774 & 0.0253 \\
BDO-PID (Guvenc & 16 & 0.149 & 0.766 & - & 0.3281 & 0.1146 & 0.0077 \\
ve ark., 2016) & & & & & & & \\
YAK-PID (Gozde ve & 25 & 0.156 & 0.920 & - & 0.4391 & 0.2224 & 0.0180 \\
Taplamacioglu, 2011) & & & & & & & \\
\hline
\end{tabular}

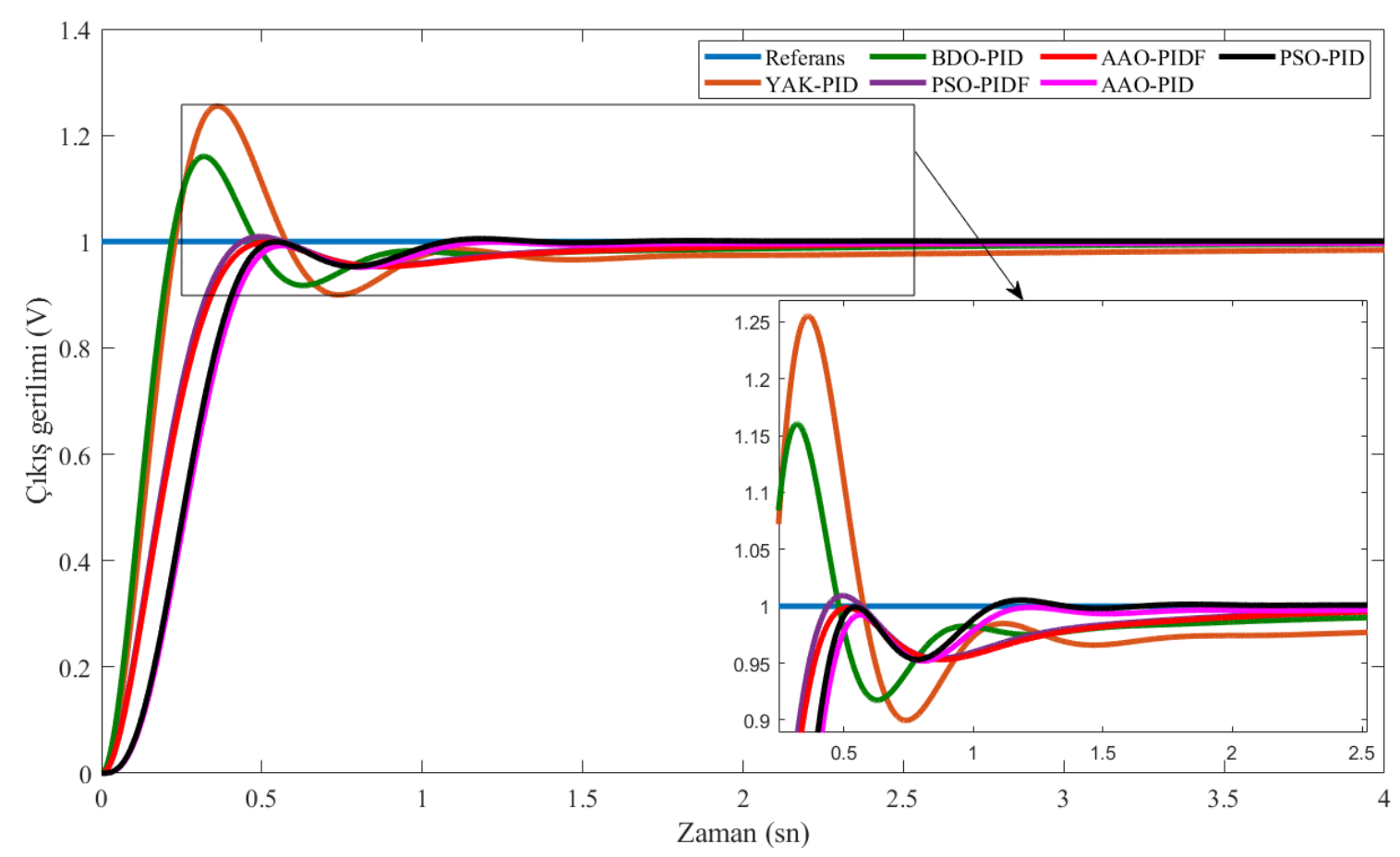

Şekil 6. Farklı PID denetleyiciler ile elde edilen OGR sisteminin basamak yanıtları 


\subsection{Kutup/Sıfır Analizi}

Denetleyicili OGR sistem kararlıı̆̆̆ını incelemek için kutup/sıfır analizi gerçekleştirilmiştir. Bu kapsamda Tablo 2'de verilen her bir denetleyici için kapalı çevrim sisteminin kutupları ve karşılık gelen sönüm oranları elde edilmiştir. Şekil 7 örnek olması amacıyla AAO-PID-F denetleyicili OGR sisteminin kutup ve sıfırlarını göstermektedir. Şekil incelendiğinde köklerin sol açık yarı düzlemde olduğu ve dolayısıyla sistemin kararlı olduğu gözükmektedir. Diğer denetleyiciler kullanıldığında da OGR sisteminin kararlı olduğu sonucu yani bütün denetleyicilerin köklerinin sol açık yarı düzlemde olduğu Tablo 4'ten çıkarılmaktadır. Ayrıca Tablo 4'teki sönüm oranları incelendiğinde PID-F denetleyicilerin tüm kutuplarının sönüm oranının 1'e yakın olduğu görülmektedir.

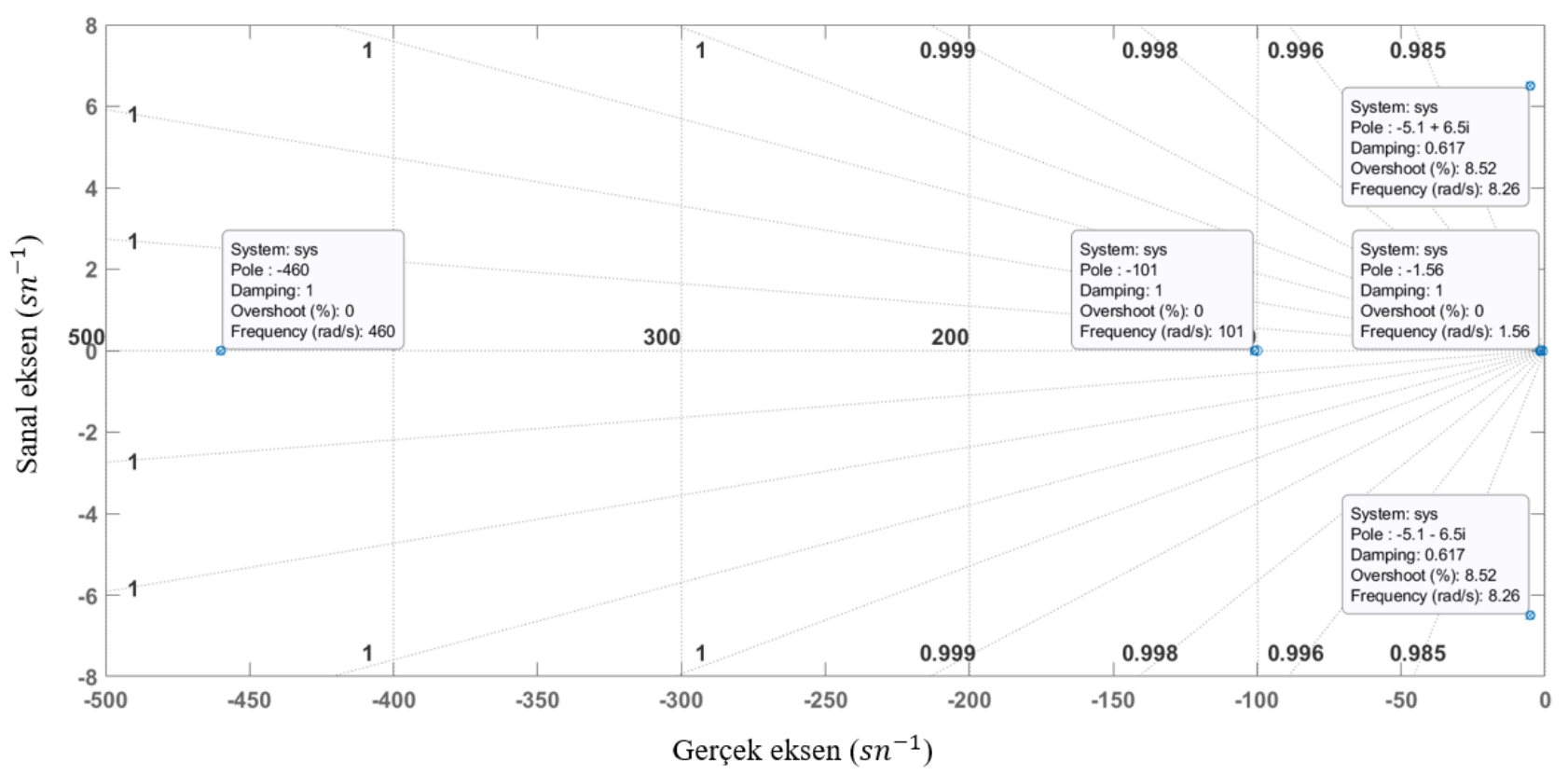

Şekil 7. Tasarlanan AAO PID-F denetleyicili kapalı çevrim OGR sisteminin kutup-sıfır çizimi 
Tablo 4. OGR sisteminin Kapalı çevrim kutupları ve karşılık gelen sönüm oranları

\begin{tabular}{|c|c|c|}
\hline Denetleyici & $\begin{array}{c}\text { Kapalı Çevrim } \\
\text { Sistem Kutupları }\end{array}$ & Sönüm Oranı \\
\hline AAO-PID-F & $\begin{array}{c}-0.93 \\
-1.56 \\
-5.1+\mathrm{j} 6.5 \\
-5.1-\mathrm{j} 6.5 \\
-101 \\
-460\end{array}$ & $\begin{array}{c}1.00 \\
1.00 \\
0.617 \\
0.617 \\
1.00 \\
1.00\end{array}$ \\
\hline AAO-PID & $\begin{array}{c}-0.164 \\
-4.87 \\
-3.68+j 9.08 \\
-3.68-j 9.08 \\
-101\end{array}$ & $\begin{array}{c}1.00 \\
1.00 \\
0.376 \\
0.376 \\
1.00\end{array}$ \\
\hline PSO-PID-F & $\begin{array}{c}-0.933 \\
-1.58 \\
-5.07+\mathrm{j} 6.69 \\
-5.07-\mathrm{j} 6.69 \\
-101 \\
-494\end{array}$ & $\begin{array}{c}1.00 \\
1.00 \\
0.604 \\
0.604 \\
1.00 \\
1.00 \\
\end{array}$ \\
\hline PSO-PID & $\begin{array}{c}-0.175 \\
-4.91 \\
-3.63+j 9.35 \\
-3.63-j 9.35 \\
-101\end{array}$ & $\begin{array}{c}1.00 \\
1.00 \\
0.362 \\
0.362 \\
1.00\end{array}$ \\
\hline $\begin{array}{l}\text { YAK-PID (Gozde ve } \\
\text { Taplamacioglu, 2011) }\end{array}$ & $\begin{array}{c}-100.98 \\
-3.75+\mathrm{j} 8.40 \\
-3.75-\mathrm{j} 8.40 \\
-4.74 \\
-0.25\end{array}$ & $\begin{array}{l}1.00 \\
0.40 \\
0.40 \\
1.00 \\
1.00\end{array}$ \\
\hline $\begin{array}{l}\text { BDO-PID (Guvenc ve } \\
\text { ark., 2016) }\end{array}$ & $\begin{array}{c}-100 \\
-4.80+\mathrm{j} 10.2 \\
-4.80-\mathrm{j} 10.2 \\
-2.1 \\
-0.585\end{array}$ & $\begin{array}{c}1.00 \\
0.427 \\
0.427 \\
1.00 \\
1.00\end{array}$ \\
\hline
\end{tabular}

\subsection{Bode Analizi}

Farklı denetleyicilerin kullanıldı̆̆ı OGR sisteminin frekans uzay analizi için bode diyagramından faydalanılmıştır. Şekil 8 farklı denetleyiciler ile elde edilen bode diyagramlarını göstermektedir. İlgili diyagramlar kullanılarak elde edilen maksimum kazanç (dB), faz marjini (derece), gecikme marjini (s) ve bant genişliği ( $\mathrm{rad} / \mathrm{s}$ ) değerlerine ait karşılaştırma sonuçları ise Tablo 5'te verilmektedir. AAO-PID-F ve PSO-PID-F denetleyicilerin sirasıly AAO-PID ve PSO-PID denetleyicilere göre faz ve gecikme marjinini iyileştirdiği tablodan görülmektedir. Dolayısıyla tasarlanan filtreli PID denetleyiciler ile elde edilen kapalı çevrim OGR sisteminin klasik PID denetleyiciler ile elde edilen kapalı çevrim OGR sisteminden daha kararlı olduğu sonucu Tablo 5 'ten çıkarılmaktadır. 


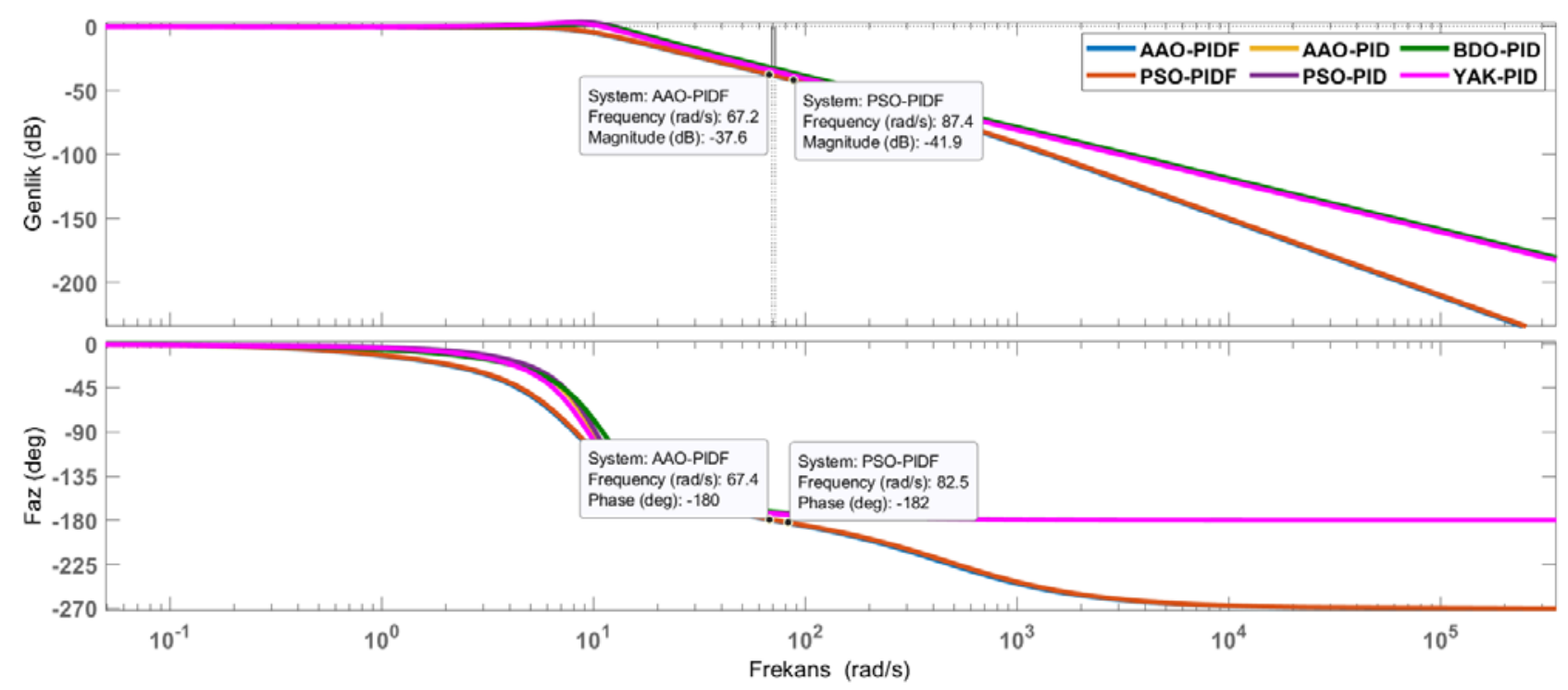

Şekil 8. Farklı denetleyiciler ile elde edilen Bode diyagramları

Tablo 5. OGR sisteminin bode çizimlerinden elde edilen sonuçlar

\begin{tabular}{l|c|c|c|c}
\hline \multicolumn{1}{c|}{ Denetleyici } & $\begin{array}{c}\text { Maksimum kazanç } \\
(\mathbf{d B})\end{array}$ & $\begin{array}{c}\text { Faz marjini } \\
\mathbf{( d e r e c e})\end{array}$ & $\begin{array}{c}\text { Gecikme marjini } \\
\mathbf{( s )}\end{array}$ & $\begin{array}{c}\text { Bant genişliği } \\
\text { (rad/s) }\end{array}$ \\
\hline AAO-PID-F & $1(0 \mathrm{rad} / \mathrm{sn})$ & 180 & $\operatorname{Inf}(0 \mathrm{rad} / \mathrm{sn})$ & 8.3292 \\
AAO-PID & $1.48(8.13 \mathrm{rad} / \mathrm{sn})$ & 63.72 & $0.093(11.97 \mathrm{rad} / \mathrm{sn})$ & 13.93 \\
PSO-PID-F & $1(0 \mathrm{rad} / \mathrm{sn})$ & 180 & İnf $(0 \mathrm{rad} / \mathrm{sn})$ & 8.6915 \\
PSO-PID & $1.53(8.48 \mathrm{rad} / \mathrm{sn})$ & 61.05 & $0.086(12.43 \mathrm{rad} / \mathrm{sn})$ & 14.38 \\
BDO-PID (Guvenc ve & $2.87(7.52 \mathrm{rad} / \mathrm{sn})$ & 69.4 & $0.111 \mathrm{~s}(10.90 \mathrm{rad} / \mathrm{sn})$ & 12.880 \\
ark., 2016) & & & & \\
YAK-PID (Gozde ve & $1.56(8.65 \mathrm{rad} / \mathrm{sn})$ & 81.6 & $0.122 \mathrm{~s}(11.7 \mathrm{rad} / \mathrm{sn})$ & 14.284 \\
Taplamacioglu, 2011) & & & & \\
\hline
\end{tabular}

\subsection{Dayanıklılık Analizi}

Son olarak, AAO algoritması ile optimal ayarlanmış PID-F denetleyicili OGR sisteminde parametre değişikliğine karşı dayanıklılık analizi yapılmıştır. Dayanıklılık analizi için yükselteç, uyarıcı, generatör ve sensör bileşenlerinin zaman sabitleri \% -50 ile \%+50 arasında değiştirilerek geçici yanıt karakteristikleri irdelenmiştir. Her bir parametre değerine ait sonuçlar Tablo 6’da verilmiştir. Bununla birlikte, kapalı çevrim OGR sisteminin her bir zaman sabiti için birim basamak yanıtı incelenmiştir. Çıkış gerilim yanıtları Şekil 9-12 arasında verilmiştir. Elde edilen sonuçlar ile tasarlanan AAO-PID-F denetleyicisinin $\% \quad-50$ ve $\% \quad+50$ sinırlarında bile OGR sistemini kararsızlaştırmadığı ve kabul edilebilir sistem yanıtı sunduğu görülmektedir. 
Tablo 6. AAO algoritması ile optimize edilen PID-F denetleyicinin dayanıklılık analizi sonuçları

\begin{tabular}{c|c|c|c|c|c}
\hline $\begin{array}{c}\text { Model } \\
\text { Parametreleri }\end{array}$ & $\begin{array}{c}\text { Değişim oranı } \\
\mathbf{( \% )}\end{array}$ & $\begin{array}{c}\text { Mp } \\
\mathbf{( \% )}\end{array}$ & $\begin{array}{c}\mathbf{t}_{\mathbf{s}} \\
\mathbf{( s n )}\end{array}$ & $\begin{array}{c}\mathbf{t}_{\mathbf{r}} \\
\mathbf{( s n )}\end{array}$ & $\begin{array}{c}\mathbf{t}_{\mathbf{p}} \\
\mathbf{( s n})\end{array}$ \\
\hline \multirow{2}{*}{$\tau_{s}$} & -50 & 0 & 0.401 & 0.286 & 4 \\
& -25 & 0 & 0.393 & 0.281 & 4 \\
& +25 & 0.3703 & 0.379 & 0.273 & 0.508 \\
& +50 & 0.8932 & 0.373 & 0.269 & 0.503 \\
\hline \multirow{2}{*}{$\tau_{g}$} & -50 & 7.7744 & 1.3050 & 0.154 & 0.306 \\
& -25 & 2.6632 & 1.0210 & 0.214 & 0.404 \\
& +25 & 0.3104 & 0.483 & 0.343 & 2.66 \\
& +50 & 1.3708 & 0.58 & 0.41 & 4 \\
& -50 & 0 & 1.1590 & 0.6560 & 4 \\
& -25 & 0 & 1.0090 & 0.2310 & 0.625 \\
& +25 & 1.3718 & 0.441 & 0.319 & 0.744 \\
\hline \multirow{2}{*}{$\tau_{e}$} & +50 & 3.1352 & 0.49 & 0.358 & 4 \\
& -50 & 0 & 0.8450 & 0.3240 & 4 \\
& -25 & 0 & 0.8230 & 0.2810 & 0.5430 \\
\hline
\end{tabular}

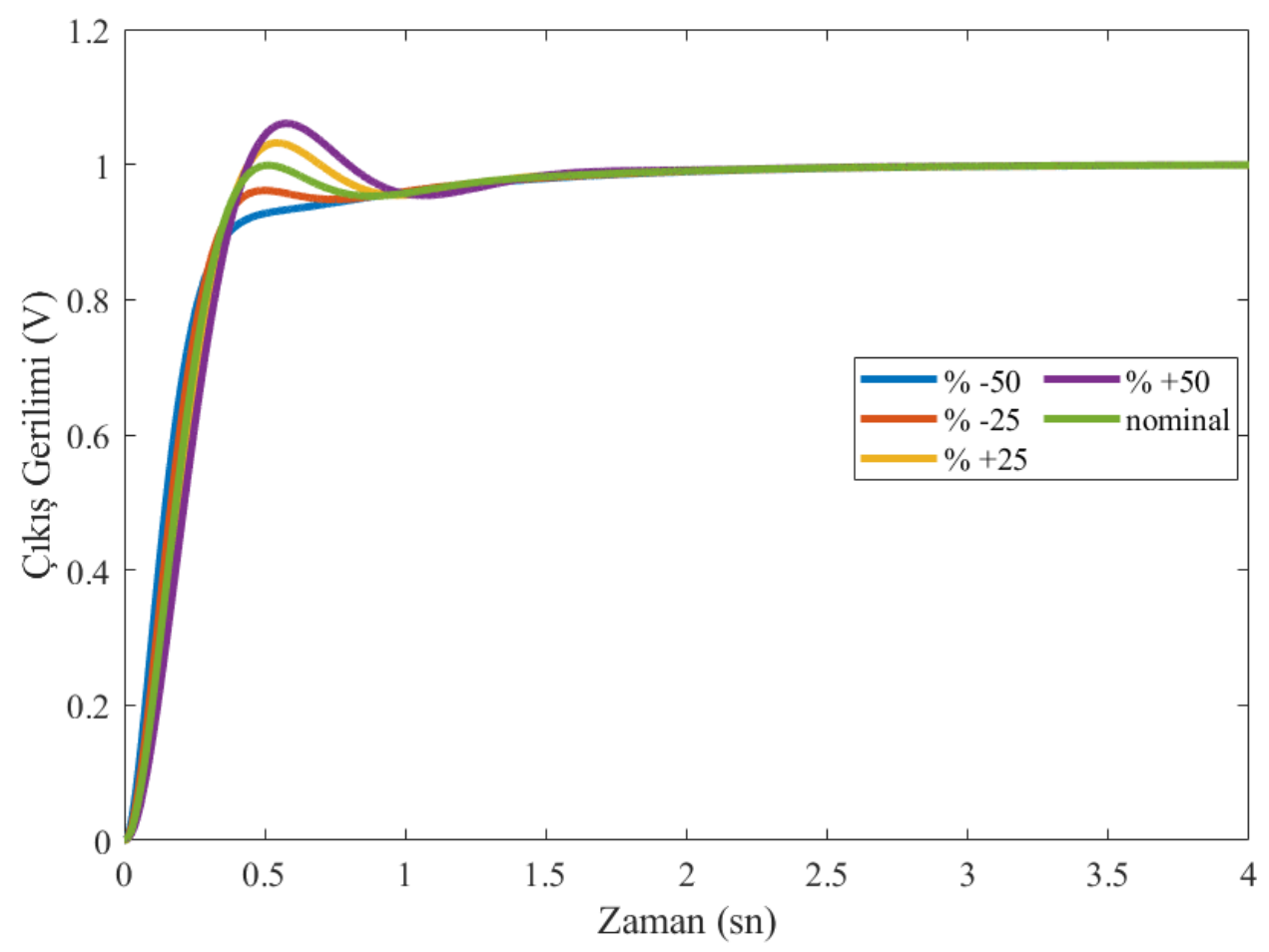

Şekil 9. AAO PID-F denetleyici ile tasarlanan OGR sisteminin $\tau_{\mathrm{a}}$ değişimi için basamak yanıtı 


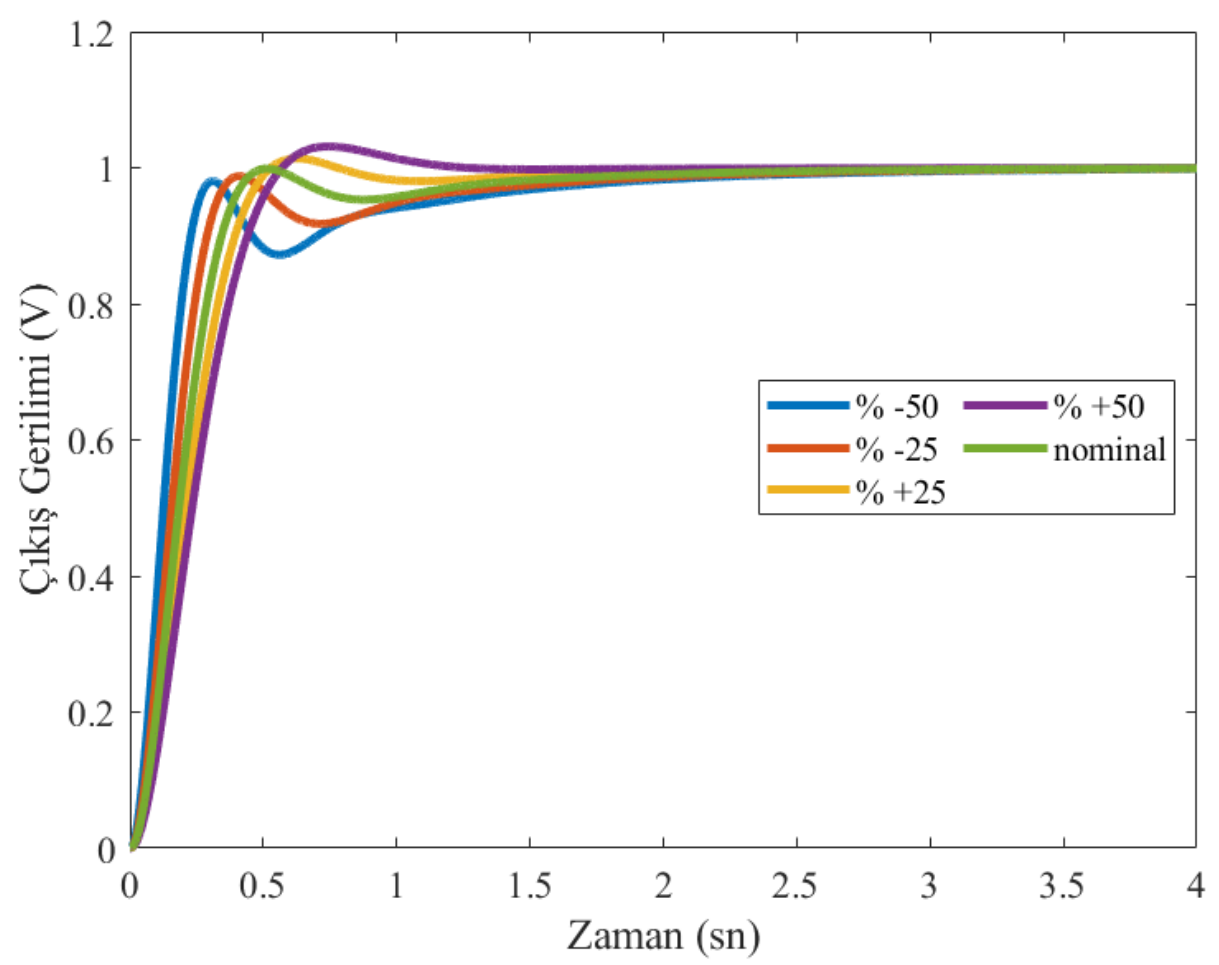

Şekil 10. AAO PID-F denetleyici ile tasarlanan OGR sisteminin $\tau_{\mathrm{e}}$ değişimi için basamak yanıtı

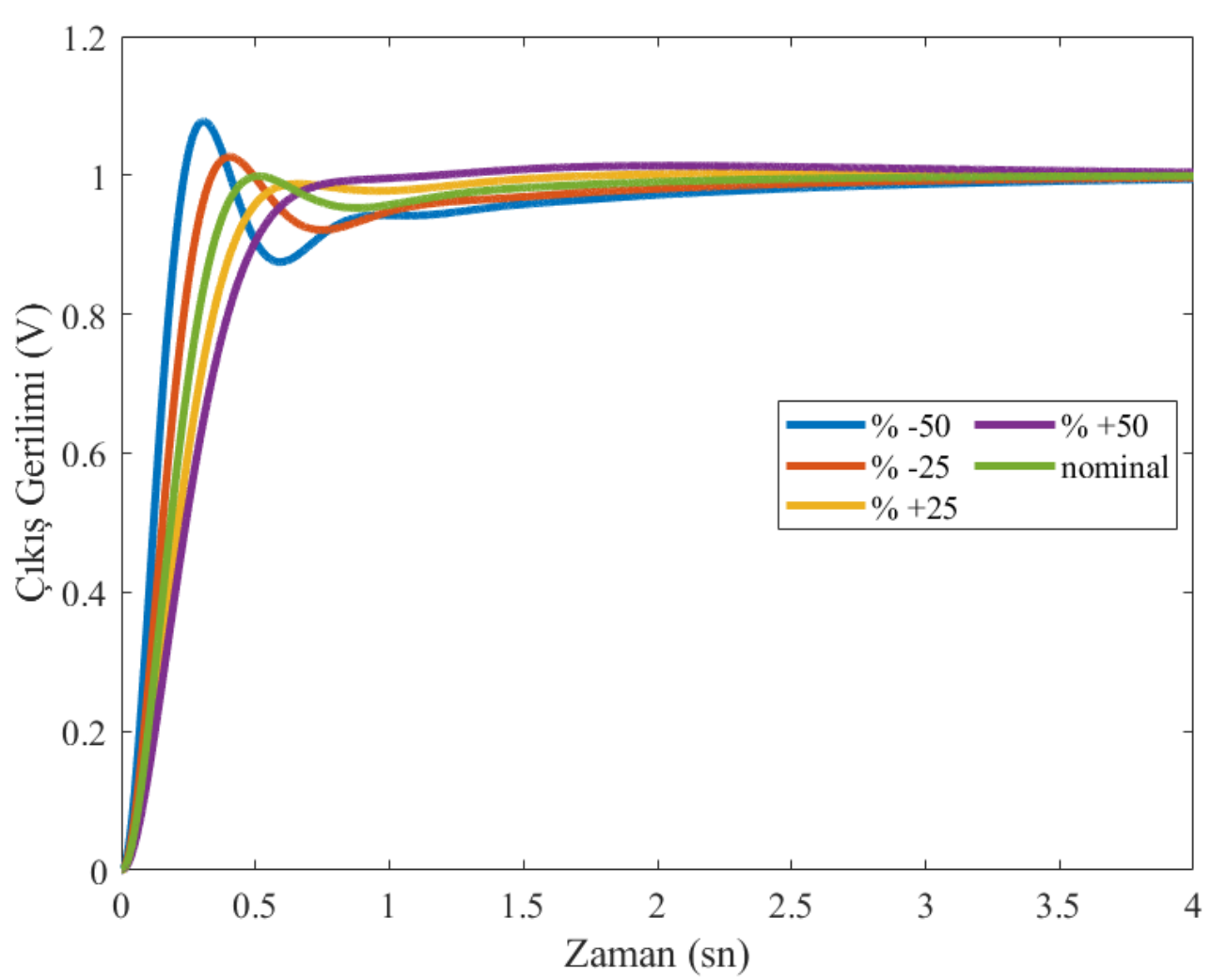

Şekil 11. AAO PID-F denetleyici ile tasarlanan OGR sisteminin $\tau_{\mathrm{g}}$ değişimi için basamak yanıtı 


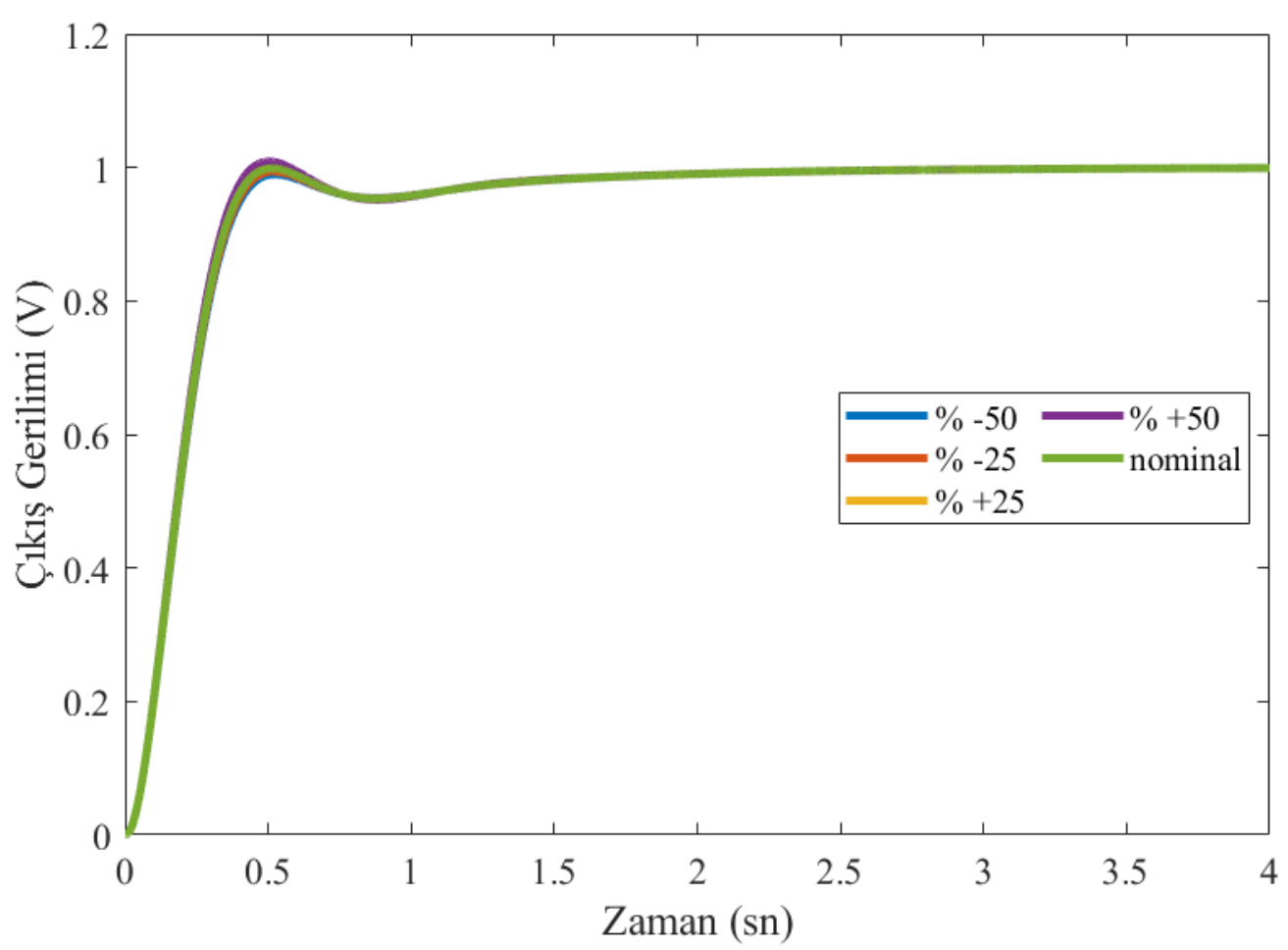

Şekil 12. AAO PID-F denetleyici ile tasarlanan OGR sisteminin $\tau_{\mathrm{s}}$ değiş̧imi için basamak yanıtı

\section{Sonuçlar}

$\mathrm{Bu}$ çalışmada OGR sistem performansını iyileştirmek için parametreleri optimal ayarlanmış PID-F denetleyici tasarımı sunulmuştur. PID-F denetleyici parametrelerini ayarlamak için hem AAO hem de PSO algoritmaları kullanılmıştır. PID-F denetleyicisindeki filtrenin etkisini göstermek için AAO ve PSO algoritmaları ile klasik PID denetleyici tasarımları da gerçekleştirilmiştir. Ayrıca literatürde var olan iki farklı PID denetleyici (BDO-PID ve YAK-PID) de göz önüne alınarak her denetleyici için, geçici yanıt analizi, bode analizi, kutup-sıfır analizi ve dayanıklılık analizi Matlab/Simulink programında gerçekleştirilerek performans karşılaştırması yapılmıştır. Elde edilen sonuçlara göre, filtreli PID denetleyicilerin (AAO-PID-F ve PSO-PID-F) klasik PID denetleyicilere (AAO-PID, PSO-PID, BDO-PID ve YAK-PID) göre OGR sistemi denetiminde daha başarılı olduğu ve OGR sisteminin kararlılığını arttırdığı gözlemlenmiştir. Ek olarak, tasarlanan AAO-PID-F denetleyicinin yükssek orandaki parametre değişikliklerine bile dayanıklı olduğu, OGR sistemini kararsızlaştırmadığı ve kabul edilebilir sistem yanıtı sunduğu gözlemlenmiştir. 


\section{Kaynaklar}

Al Gizi, A, J., (2018). A particle swarm optimization, fuzzy PID controller with generator automatic voltage regulator. Soft Computing, 23, 8839-8853.

Anbarasi, S., Muralidharan, S., (2016). Enhancing the Transient Performances and Stability of AVR System with BFOATuned PID Controller. Control Engineering and Applied Informatics, 18(1), 20-29.

Ayas, M. S., (2019). Design of an optimized fractional high-order differential feedback controller for an AVR system. Electrical Engineering, 101, 1221-1233.

Bingul, Z., Karahan, O., (2018). A novel performance criterion approach to optimum design of PID controller using cuckoo search algorithm for AVR system. Journal of the Franklin Institute, 355(13) 5534-5559.

Blondin, M. J., Sanchis, J., Sicard, P., Herrero, J. M., (2018). New optimal controller tuning method for an AVR system using asimplified Ant Colony Optimization with a new constrained Nelder-Mead algorithm. Applied Soft Computing, 62, 216-229.

Bourouba, B., Ladaci, S., Schulte, H., (2019). Optimal Design of Fractional Order PID Controller for an AVR System using Ant Lion Optimizer. IFAC-Papersonline, 52(13), 200-205.

Coelho, L. S., (2009). Tuning of PID controller for an automatic Voltage regulator system using chaotic optimization approach. Chaos, Solitons and Fractals 39 (4) 1504-1514.

Çelik, E., Durgut, A., (2018). Performance enhancement of automatic voltage regulator by modified cost function and symbiotic organisms search algorithm. Engineering Science and Technology, an International Journal, 21, 1104-1111.

Gaing, ZL., (2004). A particle swarm optimization approach for optimum design of PID controller in AVR system. IEEE Transaction on Energy Conversation, 19(2), 384-391.

Gozde, H., Taplamacioglu, M. C., (2011). Comparative performance analysis of artificial bee colony algorithm for automatic voltage regulator (AVR) system. Journal of the Franklin Institute, 348 (8) 1927-1946.

Guvenc U, Yigit T, Isik AH and Akkaya I (2016) Performance analysis of biogeography-based optimization for automatic voltage regulator system. Turkish Journal of Electrical Engineering and Computer Sciences 24(3): 1150-1162.

Hameed, N. S. S., Othman, W. A. F. W., Wahab, A. A. A., Alhady, S. S. N., (2019). Optimising pid controller using bees algorithm and firefly algorithm. ROBOTIKA, 1(1), 22-27.

Hekimoğlu, B., Ekinci, S., (2018, June). Grasshopper optimization algorithm for automatic voltage regulator system. 2018 5th International Conference on Electrical and Electronic Engineering (ICEEE) (pp. 152156), Istanbul.

Hekimoğlu, B., (2019). Sine-cosine algorithm-based optimization for automatic voltage regulator system. Transactions of the Institute of Measurement and Control, 41(6), 1761-1771.

Kennedy, J., Eberhart, R., (1995). Particle Swarm Optimization, Proceedings of the IEEE International Conference on Neural Networks, 4, 1942-1948.

Sahib, M. A., (2015). A novel optimal PID plus second order derivative controller for AVR system. Engineering Science and Technology, 18, 194-206.

Sambariya, D. K., Paliwal, D., (2016). Optimal design of PIDA controller using harmony search algorithm for AVR power system. 2016 IEEE 6th International Conference on Power Systems (ICPS) (pp. 1-6). New Delhi.

Suribabu, A. G., Chiranjeevi, B. T., (2016). Implementation of Fractional Order PID Controller for an AVR System Using GA and ACO Optimization Techniques. IFAC-Papersonline, 49(1), 456-461.

Tang, Y., Li, X., Wang, Y., Li, N., Han, M. ve Liu, F., (2017). Optimal fractional order PID controller design for automatic voltage regulator system based on reference model using particle swarm optimization. Int. J. Mach. Learn. \& Cyber, 8, 1595-1605.

Verma, S. K., Yadav, S., Nagar, S. K., (2017). Optimization of Fractional Order PID Controller Using Grey Wolf Optimizer. J Control Autom Electr Syst, 28, 314-322.

Zhao, W., Wang, L., Zhang, Z., (2019). Atom search optimization and its application to solve hydrogeologic parameter estimation problem. Knowledge-Based Systems, 163, 283-304. 